\title{
TALES OF EPHEMERAL EXISTENCE: BETWEEN SCULPTURES, PICTOGRAMS, AND PHOTOGRAPHIES
}

\author{
JULIÁN DAVID ROMERO TORRES
}

\begin{abstract}
This article, the purpose of which is to place photography into the discussion, has been developed through the different social sciences with which it particularly deals with the anthropological, historical and social significant elements that include tales of human groups, the means of defining their existence, and rituals and manners of constructing relationships with environmental, social and cultural surroundings. The paper has six sections, starting with an introduction. The following chapter provides some keys to understanding the possible connections between sociology and photography. The third part develops a discussion of the place of the anthropological field in recognizing photography as a human and cultural practice. The next chapter opens a debate about photography, through the results of a case study in Colombia involving a discussion about the family, the construction of visual speech, the tales that individuals create in a family album, and the possible distortions and interest in building particular dialogues about the past. We conclude with theoretical reflections about the important place of visual narration and the construction of collective memory in the institution of the family. In this way, we show the continuously constructed tales that unveil the human sojourn in the world. In the same way, the family as an institution is one of those human groups that uses tools such as photography to construct their stories and their official collective memories in oral and visual discursive narrative codes.
\end{abstract} KEYWORDS: photography, tale, family, collective memory, sociology

1 Julián David Romero Torres is a Ph.D. student at ELTE University, Budapest; e-mail: simeranesi@gmail.com 


\section{INTRODUCTION}

The purpose of this text is to highlight the topical discussion in the social sciences - and in particular, in the sociological discipline - about social character that involves photography in many of the narratives and tales about human groups.

Academics are urged to engage in dialogue with disciplines and researchers that have thought about the problems of visual practices and, in particular, about the social practices of photography that may open up lines of reflection about this barely scrutinized field. For this purpose, some clues should be provided to help understand the possible relationship between sociology and photography in the sense of identifying historical connections in the nineteenth century, since the social disciplines have become molded in the shape of the scientific method, and since photography was invented as a scientific product thanks to advances in chemistry and physics.

Second, the development of the anthropological condition of thinking about human existence in terms of images, with all the fantasy and hues of reality this involves, demonstrates that the elements required to talk about the relationship between photography, history and myth exist, and can be used empirically to represent another perspective. Furthermore, the family practice of photography has some overtones and shades that necessarily fertilize the sociological discussion.

Topics such as oblivion, memory, album, death, image, temporality and print, inter alia, are appropriate for use in a fruitful discussion that has not only the purpose of affirmation, but also of interrogation, of questioning, and of creating possible avenues for areas of work about the subject matter that is presented. In this direction, we will try to put into the discussion, in a phenomenological way, the conception of photography in family integration through a case study carried out in Colombia in 2009 during a process of fieldwork for a sociology research thesis ${ }^{2}$ in which several experiences with different families in Colombia were included. With this, the objective is to construct a discussion about how the family creates visual speech with different objectives and characteristics, and when rituals, collective story and memory construction, institutional speech and truths and lies, can be filtered through the photographic tale to reveal its negatives. In sum, one of the goals of this article is to provide some analytical keys for developing a specific debate about the relation between the construction of photographic family tales and some approaches from the social disciplines.

2 "Photography of family: Characterization of the photo story in Colombia. A case study." Julian Romero. Universidad Santo Tomás, 2009. 


\section{SOME KEYS TO UNDERSTANDING THE CONNECTION OF SOCIOLOGY TO PHOTOGRAPHY}

Thinking about photography as a means of problematizing in social sciences represents a prolific approach, not only because this goal been addressed infrequently compared to other well worked over topics, but also because of the quality and depth of the investigations that have been undertaken so far, and the possibility we have to discover creative paths that allow us to identify questions with which to probe deeper.

Sociology and photography are not spatiotemporal coincidences: their forms and means of enunciation have not been free of constraint, and fewer have been the opportunities that made it possible to think and act sociological and photographically. Photography - as a modern instrument - was consolidated in the first half of the nineteenth century, while during the same period Comte discoursed about positive philosophy (Cours de Philosophie Positive), delineating a new and visionary way of knowing and apprehending how the world would unfold in the light of the scientific method. Photography and sociology were two fields in gestation that tried to build their means of enunciation, each one "in its own way" and through "its own words," but necessarily obeying the constraints of a period that allowed the concretization of the desire to capture the world of the external, one on the plates of the daguerreotype, and the other through theories and methodologies, thereby constructing themselves a reference $-\mathrm{a}$ "disorder," in the words of Roland Barthes - one in the process of being born for centuries: the advent of "myself as other," converting "subject to object."

The vision of the world through the telescope of the telephoto lens has, then, started, for the new positive spirit of Sociology. Photography and sociology are partner disciplines, French by birth, related from their beginning. Both born in Europe, exported to America, and are re-imported at the end of the twentieth century from the United States to Europe. (De Miguel, 1998)³

The year 1839 is universally declared the date of the new discovery of photography, and France the land which gave birth to the architect of the invention...! The first photographer in the world! But it has been modern European society that has engendered - through its culture - accurate theories about the actual conditions of the nineteenth century. Positive philosophy found determinism lacking in the idea that every goal of knowledge absolutely - i.e.

3 Translated by the author. 
indissoluble truth - was being revealed through science, through the antiseptic observation of nature, through its post-transformation and dominion with the aim of bringing about the new order. It was claimed that science must solve the social problems produced by the bourgeois revolutions. After producing the disorder that bought about the change in monarchical structures, the bourgeois now needed to conserve and sharpen the goals that had been achieved, to correct problems and to produce - in all ways - the structures of the capitalist system: a Historic science that would erect monuments to big individuals, about the evolution of towns, the restless search for the indissoluble truth, and the construction of instruments capable of revealing the truth in order to examine the civilization of knowledge, of realism, of the veracity of proof, of time, of landscape and nature. Holding on to positivism - the idea that all wit creates a knowledge of reality that can be acquired from what we can observe through the senses or mechanisms that check the authenticity of the observed - the best tool for accomplishing these wishes would be photography itself, being able to create a faithful image of reality and a copy of nature. As Batchen states: "No doubt photography did eventually become a popular metaphor for the possibility of a positivist view of the world" (Batchen, 1999).

In terms of framing the relationship between humanistic and photography research, I propose two paths which have nowadays become essential; two fields of work (and more could exist more if the creativity of some were explained). The first one involves defining photography as an object of research and problem analysis - as desired -, in the dispositive of the social sciences. Sociology, History, Anthropology, Semiotics, inter alia, act with no disciplinary segments dedicated to the problems and vicissitudes of the visual in our society and its individuals; yet this is an emerging field of discussion, dissertation, and rigorousness, where we think of ourselves - as homo videns - as societies of images. The second approach envisages the concept of the construction of photography as an instrument of social analysis, a capturing technique, as files or prints of social groups that generate clues about some problems.

"Photographic theory applied to the analysis of the society is really undeveloped. Photography is accepted as art, as chemistry, sometimes even as a complaint, as a hobby, but not as Sociology" (De Miguel, 1998). ${ }^{4}$ This claim is an affirmation of the perspectives of Jesús de Miguel and Ponce de León, two academics that risked writing a text entitled: "For a Sociology of the photography," a short article that is written in a tone of incitement that poses the necessity of consolidating a theoretical and methodological perspective for thinking about that daily activity of creating pictures. The former are convinced that photography is an

4 Translated by the author.

CORVINUS JOURNAL OF SOCIOLOGY AND SOCIAL POLICY VOL. 9 (2018) 2 
analytical tool of social facts as much as a social activity. They affirm that any researcher who wants to know about photography and sociology must work with three types of image - let us call them ideals - namely, the photo-window, which aims to represent the external world, the metaphor of the window that is open and allows us to see into the exterior, with the intention of reproducing exactly what is seen (involving an empirical and detailed photo of reality; a segment of reality). On the other hand, there is also the photo-mirror, which gives an account of the photographer's own feelings that permeate their frames. The last form is the photo-rule, which represents those photos that are taken with the aim of a "social control strategy" ("advertising"), and through which on an unreal world are imposed certain manners of wearing, thinking, buying, and wishing.

If we analyze the photography of families, of political campaigns, of the sensationalist press, we do not find that such a division is arbitrary, but it is nonetheless almost useless in the sense of all forms of photography which are impregnated with all of these three characteristics, and more. We cannot be constricted by the rationalist goal of trying to stuff the multiplicity of overtones that the social world has into a couple of categories.

\section{Anthropological approaches to some issues with image}

From an evolutionary perspective, human groups have always constructed marks by which they have expressed, recorded or developed the sense of their social being and the cosmogonic, cultural, mythic, and organizational content of those ephemeral existences which civilizations must encounter.

Rupestral manifestations are expressions of ancient, historical and prehistorical cultures that have materialized their vital existence in engravings, pictograms, petroglyphs, sculptures... Carved in rocks - in a mono or polychromatic way - similarly, showing the ways in which different cultures become exhibited in images. Sculptures buried thousands of years ago in the area of San Agustín, Colombia - a town of sculptors about which nobody knows anything except what has been interpreted and studied through its sculptures buried 5000 years ago show anthropomorphized creatures with jaguar features: an ancient symbol of force and wisdom from America. According to the inhabitants of this area, they are an artistic and religious legacy of humanity. During trips to the area years ago, I was told by a guide - a farmer on his horse - that "The sculptures that were left by this culture were like photographs of themselves. Thanks to the sculptures we can know how they looked." This statement, contributed by Aníbal, is important to preserve in relation to the human need to express itself - our countless manners - on the earth, and maybe the uncertainty of death, oblivion and memory, and in 
how we describe and leave images of ourselves: "Photography is just one more link in the chain that started with facial pictograms in rocks and walls" (Silva, 1998) ${ }^{5}$ : one more link in the world's tales and the use of language that have been used to express and manifest, as shown in tangible products of human activity. It is not impossible to think about a time - maybe centuries, maybe millennia from now - when the modern project is extinguished, and with it the family, but can still be found in those worldly edifications a dusty and forgotten book in which there are preserved a series of curious images of an institution that lived at one period; there is no audacity in thinking that the photo album of the modern family may be the element with which future civilizations realize how social life developed, and understand that there was a civilization that was also displayed/constructed in images through some of the techniques used to perform such a function, in this case; photography.

This element and anthropological condition of constructing existential and vital tales unveils an uncertainty and the imminent fear of oblivion, irreversible time, natural avatars and the death that has made men create - as a weapon knowing. This is one of the transcendental idea of Nietzsche's work: the idea that to determine and exercise control over humans and their surroundings man constructs speeches that allow him to cheat himself about the basis of his world, obtaining the status of truth for all human dissertations and expressions over himself, using language as fixation and structure. "For that which is to count as 'truth' from this point onwards now becomes fixed, i.e. a way of designating things is invented which has the same validity and force everywhere, and the legislation of language also produces the first laws of truth" (Nietzsche, 1999).

This is why photography is not so dissimilar to petroglyphs, nor sculptures, nor the portrait-painting of the Renaissance in the sense of being an analogical creation to the person that makes it possible. But is it pure analogy? Of course not! As previously stated, the Agustina culture ${ }^{6}$ sculptures involved certain permutations whereby men appeared with animal characteristics (tusks, snakes, jaguars, and eagles) that represented mythological creatures and a whole religious conception of the world, because these shapes that the human body takes on could only be achieved through ritual and their own sacrifice. This issue demonstrates that, at the time of being represented in a rock sculpture, there could be no reliable portrait of mans' physiognomy, way of dressing and acting in daily life, but rather such portrayals obey a metaphysical and ritual

\footnotetext{
5 Translated by the author.

6 Concept attributed to the cultures that lived in this territory of Huila - Colombia, which, lacking a name that differentiates them, are called this because San Aguntín belongs to the colonial - Spanish period.
} 
conception, as if when sculpting these impressive rocks certain exceptional moments must occur to be spoken of in the stones.

\section{PHOTOGRAPHY AMONG RITES, FAMILIES, AND LIES. A CASE STUDY}

Can it be that photography has emerged as the most impartial, veridical, reliable technique of making representations in images?

Taking a look at family photography, we find that it captures moments appropriate for being solemnized, even if it is not true that pictures are increasingly taken of baptisms, birthdays, first communion, and weddings as the important topics repeated in family albums: again, photography portrays ritual creatures that change their position and their clothing, thus perhaps photography involves a break in the daily routine in which to give light to a group image revealing its ritual nature as a technique of preserving "good moments," as if firing the flash and fixing the light in the film must happen at certain solemn moments worth being related in pictures.

In this case, photography is related to rites or solemn situations for the family: here, photography is understood in Bourdieu's terms as "a technology for the reiteration of the party" (Bourdieu, 1990), being the photographic moment in other domestic rituals: colloquially, a wedding without any time for photographs is not a wedding. This is curious, and suggests that most of the time during a celebration, in terms of the former examples, the ceremony in the church and the beginning of a party are dedicated to photography, and the prefiguration of group and couple poses. Being radical means claiming that such events only become significant if there are cameras to relate, demonstrate and even taxidermize them.

The imperialism of the photographic camera in individual lives indicates that social necessity of demonstrating and reinforcing moments which are imbued with feelings and interests, possessing the elements of truth of an organization that requires reaffirming day to day - as "group" - and being capable of demonstrating to the public in general that family ties are unbreakable, and this is one of the duties that the family has conferred to photography: a memory store. Martha Guzmán de Bolivar, mother of the Bolívar-Guzmán family in Bogotá, Colombia,? stated the following about photography:

7 Interview from 2009 in the frame of research of the sociology thesis "Photography of family: Characterization of the photo story in Colombia. A case study." Julian Romero. Universidad Santo Tomás, 2009. 
"It is not much about the past, it is about having a living memory. What happens is that it seems that always it is present, but in time it becomes history because you are constantly a function of the family and you are taking pictures."

The institutionalization of memory occurs in the fact of photography as a form of speech; it means preserving a moment in the album, thereby stipulating what is memorable in the family, and thus also what is susceptible to being forgotten. When Mrs. Martha is asked about showing her pictures, she says:

"Looking out for the remembering of somebody else: Do you remember that we were there? That we did many things? Ay! Look at that landscape... because it is the only thing remains to us, it is the only memory that remains to us."

In this way it can be seen that photography has a clear function in the family: it is aimed at institutionalizing a common past, and also for generating a group identity, while the past is presented as unique, indivisible and absolute, and images are presented as irrefutable truth of the past. This means that feelings of the irreversibility of time have weight, but at the same time so do those of irreversibility in the sense that family members cannot forget that they are part of a group that has lived exceptional moments. The album, that family chronicle, evidence of a visually fragmented history, occasional and totally aimed at pragmatic issues in this case of memory: it creates a capital biography of the family, showing that pleasant moments are ephemeral and susceptible to being forgotten (in contrast to unpleasant ones), being the components for identification with morality, some traditions, aesthetic and mannered practices which from generation to generation are reproduced (considering the desperate change of the ages) in the rituals of the group and are fixed and filed in a family compendium. As Bourdieu says: "The family album expresses the essence of social memory. There is nothing more unlike the introspective 'search for lost time' than those displays of family photographs with their commentaries, the ritual of integration that the family makes its new members undergo" (Bourdieu, 1990). The family is seen as an image hunter that can talk about itself, forget about itself, reminisce with itself, and identify with itself: "Taking pictures is like taking notes a little bit, trying at the same time to remember, and giving a license to forget. It is a process of mental hygiene" (Bourdieu, 2003). ${ }^{8}$

8 Translated by the author

CORVINUS JOURNAL OF SOCIOLOGY AND SOCIAL POLICY VOL. 9 (2018) 2 
This concept has the power that psychoanalysis applies to understanding phenomena as manifestations not only of the positive, but also the reverse: "Album stories are wishes with a sometimes contrary and perverse logic of manifesting (...) the album constructs a visual memory, but also the contrary: oblivion" (Silva, 1998) to the extent that the evidence is cut, leaving a section of the photographic story. If it is said that photography solemnizes what is solemn, then what is not solemn, what is the family hiding, what constitutes the nonfamiliar, the non-ritual?

"What happens is that in sad moments pictures are generally not taken because the sorrow is so great that it does not have a place; even having a camera in the pocket, such a trauma, the issue... that you do not even think of taking a photo."

These are the words of Mrs. Martha when asked whether she would place a sad picture on her bedside table. This fact urges thinking about the idea that the photo album is closer to a book in which is rewritten an institutional history, full of happy, funny and pleasant tales which aims to create a positive vision of the family, saved as one of the cultural referents, a place where comedy is rewritten. Aristotle in his poetics - as quoted by Silva - says: "The risible is a defect and an ugliness with no pain or harm; thus, for example: the comic mask is ugly and deformed, but with no expression of pain" (Silva, 1998). ${ }^{10}$ However, a grimace may be similar to laughter (and vice versa), and with this we understand that the nature of the tales in photography are far from being tragedies, in the literary sense of course, because dialectically they are comedy, and an album filled with this matter is used to reorganize the past as the intentional speech of the good, of the morally acceptable, of what makes us laugh, as mere mockery of what was "ours" in a bygone age.

When Mrs. Martha is asked about whether photography works for "watching the time pass," she says:

"Now we mock ourselves: when we were young, we dressed rock and roll without understanding that that time was a particular age, but now it is mocked."

This historical character can be seen when looking at family photography that contains images of many predecessor generations (as in the case of Bolívar-

9 Translated by the author.

10 Translated by the author. 
Guzman, which is a typical Latin-American family) in which unintentionally appear historical trends, ways of dressing according to the type of music that was listened to, ways of showing oneself in images. Obviously, these objects, modes and ways of identifying with one or another thing at the same time are reflected, proving the cultural past of some inserted characters in a social logic of identity, showing them as part of an era that welcomed them.

It is clear that the album preserves images, objects or parts of the body that evoke memories, and in relation to that uncertainty - due to the irreversibility of time, old age and imminence of death - memories have a function in maintaining cohesion in a group around an institutional discourse, images that connote the cultural forms of a group located in context. But there are also everyday situations that are inconceivable to the familiar shutter and the subsequent file: there are some acts that people want to be forgotten: thus what is revealed is a reflection of what is not shown... the negative of the film.

This is why the family revealed in photography must be willing to reflect what is morally acceptable; it must construct images from socially acceptable ways and manners, from popular aesthetic rules, from poses and functional themes that are the normal photographic themes of albums and paintings that are consistent with their institutional condition and value the state that makes them possible.

A popular adage preaches that "The only sure thing we have in this life is death," and photography, in the words of Castel: "is the representation of an absent object as absent," not necessarily in the sense of those who have died and still remain visible in the pictures, but also in the intention of keeping images in a present that is dying second by second, that is escaping at such a speed, that must be set in past time, because photography, first of all, is set in past time, and reveals what has melted away in days, the death of days, and which - photography - has been consolidated as the privileged instrument of social memory, conserving the force of reviving indissolubly the memory of the disappeared, of their imminent fading in time. It is about remembering that at some moment they were alive, but reaffirming that they are now dead and buried. Of which Mrs. Martha comments:

"You take the picture without thinking... and when you realize, you see that a long time has passed: this picture was taken thirty years ago! But without intending it, life and time are passing by, and the picture precisely appears to remind us that time has passed: let's say, my little girl was one year old, and now she is twenty-two. Time passes unceasingly." 
When Martha is asked about whether photography only works for solemn moments, she says:

“...not solemn at all, they could be quotidian, because at any moment somebody is beautiful and a picture can be taken, even if it is not a party; but no sorrows, not even in those moments do we think of photography. The human condition does not allow photographs like that, let's say, of a dead person."

On this point, Bourdieu claims that popular photography provides a means of making solid realities perceptible and showing them in their temporal valuation; in other words, what is shown in familiar photography is not necessarily a practical de facto fact, but is the action made past, made time, while the picture acquires its importance as long as it is evocative and possesses the social signification that identifies and is located in time. This is why, when a photo album is shown, the person who observes it is transported to a familiar past time, as long as the pictures that they see - and hear about - have context, both for the one who shows, and for the one who observes, that makes each picture part of a whole. Then, the entire album has a literary overtone and is a temporal expression.

Talk of oblivion and memory, an unwavering dialectic relationship, motivates the introduction of the variable of time, the time of photography, into the discussion. One of the peak conditions of photography is that part of the literary and narrative expressivity of a picture tells us correctly that this is how it has been - "a record of what is not anymore" (Silva, 1998)11 - and this particularity makes it received in the family as the truest and credible technique for telling tales about a group: "Being past, it constitutes an authentic proof of reality" (Silva, 1998). ${ }^{12}$ Images from the past acquire enough force to say what is considered to be "truth." In conclusion, Castel delights us with the following affirmation: "Photography (...) organizes temporality actively, takes rational precautions against the escape of time, conserving their prints. When it goes back to the expired past, that makes it nostalgic contemplation, thus it is a record equivalent to that of poetic elegy" (Bourdieu, 2003). ${ }^{13}$

In the interview with Mrs. Martha in her apartment in the city of Bogotá, a delicate topic was broached: the death, some years ago, of one of her children, linked to the pictures that portrayed him. When those pictures appeared in front of her eyes, with tears appearing and breaking voice, she said:

11 Translated by the author.

12 Translated by the author.

13 Translated by the author. 
"The family always remembers him. Ay! Julián would say this! Then loving or not loving him is so sad, but he is always present, even whether he is only in the pictures or in the sayings. Moreover, when we see the little grandson (his son) we also remember him."

"The Photograph always carries its referent with itself, both affected by the same amorous or funereal immobility, at the very heart of the moving world: they are glued together, limb by limb, like the condemned man and the corpse in certain tortures" (Barthes, 1981). It is its nature and curse that the image of the referent remains for a long time in the picture, intact, immobile, with some luck, in like reflection and likeness, as a double of it-has-been and a condemnation of the one who looks at THE picture.

"By attesting that the object has been real, the photograph surreptitiously induces belief that it is alive, because of that delusion which makes us attribute to Reality an absolutely superior, somehow eternal value; but by shifting this reality to the past ("this-has-been"), the photograph suggests that it is already dead" (Barthes, 1981). The strength of photography is when it involves the revelation of a loved being who has disappeared and is maintained thanks to its connotative matter; that is, what it refers to. That is why, according to Barthes, a photo does not contain signs because it is analogous to reality, but because it lives to refer and to connote the world and hence is able to move, to open up the dimension of memory and irreversible time, provoking a mixture of pleasure and pain, as if looking at a photo of a being or significant situation activates the switch of nostalgia.

In order to illustrate this fact I recall a visit I made to a friend's family house in Bogotá, Colombia. My friend Alejandra (one of the family's daughters) showed me some pictures from the parents' marriage in the personal drawer of her parents that had been taken from the family photo album. The couple was going through a difficult period of separation, and the pictures had something similar about them: whenever the woman appeared, she had been scratched out with a pen - her body, her pose, her clothing, her happiness with the father. From all of those images where the couple were together, she was the only one who was made to disappear. Death, love and distance, melancholy. What motivates Barthes to write Camera Lucida is precisely the recent death of his mother and his desire to reclaim her. It is there, in front of her picture, that he reflects:

Every photograph is somehow co-natural with its referent, (...) overwhelmed by the truth of the image (...) I call 'photographic referent' not the optionally real thing to which an image or a sign refers but the necessarily real thing which has been placed before the lens, without 
which there would be no photograph. (...) In Photography I can never deny that the things has been there. There is a superimposition here: of reality and of the past." (Barthes, 1981)

There at some moment was a ritual moment, the happiness about a marriage, for the communion and foundation of a family endorsed by religion and the state, being told by photography, and now there is also suffering due to a lack of love and household defragmentation. Should we also resort to defragmenting part of the visual record (isolate these pictures from the album), as well as erasing, crossing out one of the characters that comprised this critical family juncture?

\section{CONCLUSION: PHOTOGRAPHY, BETWEEN STORY AND HISTORY}

At this juncture the point must be raised that the tale, by being a tale, is fed by some fictional matter, and is thus closer to a literary expression than a historical one. However, it also contains a historic part - because what is historic? Barthes himself wondered about this, saying: "Is History not simply that time when we were not born (...) History is hysterical: it is constituted only if we consider it, only if we look at it" (Barthes, 1981). History understood as a tale comprised of facts from the past, facts passed through the filter of a tale, of a pen, of a lens or a human carving, necessarily passes through subjectivity encased in objectivity. It is because of this that it can be said that a family history is constructed in a photo album only if history is understood as a tale that does not differ from being a literary work; that is to say, it is narratively assisted to highlight certain things, expand some others, frame the best, and ignore the obtuse.

However, it is necessary to differentiate between narration, tale, and history. In terms of narrative it should be said that this is the matter which tale is made from, while in terms of actors, the narrator is he who constructs a speech being fictional, which tends to be realistic or poetical -inside the picture, inside the album, and a virtual instance, in Silva's terms: meanwhile, a tale is what is detached from the narrative, a rapporteur is he who talks about pictures or the album, tells a story with the narrative resources with which albums are made, constituting himself as a pragmatic being. From this perspective, a family would be the collective narrator of its own history and the rapporteur would be the person from the family - who, finding this technique significant for them and for the group - is capable of telling the album's history, making it verbal speech for others, and also of being able to make reflective the importance of this practice to family life. 
Each institution that has adopted photography as its modus operandi has its unique story, its way of representing itself and the speeches that sustain and reproduce. To exemplify, police photography is linked directly to the criminological and juridical institutions that monitor, control, punish, and verify, while journalistic photography deals with the stories of documentation, segmentation and sensationalism from media that favor certain discourses. Furthermore, advertising photography deals with mass consumption and industry, whereas art photography projects the cultural elite, intellectually sterile and politically conservative. And... family photography?

Here we should ask ourselves, what has happened with the photo album? Where is that album now? How do we see ourselves, and want to see ourselves, in the photos that millions of individuals can see from behind their screens?

\section{BIBLIOGRAPHY}

Barthes, Roland (1981), Camera Lucida: Reflections on Photography. Hill and Wang: New York.

Batchen, Geoffrey (1999), Burning with Desire: The Conception of Photography. The MIT Press, Cambridge.

Bourdieu, Pierre (1998), Photography. A middle-brow Art. Polity Press, Crambridge.

Bourdieu, Pierre (2003), Un arte medio, Gustavo Gili: Barcelona.

De Miguel, Jesús; Ponce de León, Omar (1998) "Para una sociología de la fotografía", Revista Española de Investigaciones Sociológicas, №84, Madrid, Centro de Investigaciones Sociológicas.

Nietzsche, Friedrich (1999) "On Truth and Lying in a Non-Moral Sense", in: The Birth of Tragedy and Other Writings. Cambridge University Press, Cambridge.

Romero, Julián (2009) "La fotografía de familia: caracterización del relato fotográfico en Colombia. Un estudio de caso". ["Photography of family: Characterization of the photo story in Colombia. A case study"]. Thesis in sociology. Universidad Santo Tomás.

Silva, Armando (1998), Álbum de familia. La imagen de nosotros mismos [The Family photo Album: The image of ourselves], Norma, Bogotá. 